\title{
PERCEPÇÃO DA INTERNACIONALIZAÇÃO PELOS EXTENSIONISTAS DO PROGRAMA INTERNACIONAL DESPERTANDO VOCAÇÕES PARA LICENCIATURAS IFPE CAMPUS VITÓRIA DE SANTO ANTÃO.
}

\author{
Apresentação: Comunicação Oral \\ Francisco Rodrigues da Silva Neto ${ }^{1}$; Rayanne da Silva Lima ${ }^{2}$; Eduardo Fragôso dos Santos \\ Silva $^{3}$; Kilma da Silva Lima Viana ${ }^{4}$, Erick Viana da Silva ${ }^{5}$
}

\begin{abstract}
Resumo: Esse artigo objetiva apresentar resultados de uma pesquisa que analisou as percepções dos estudantes do curso de Licenciatura em Química no Instituto Federal de Pernambuco - Campus Vitória de Santo Antão e que também fazem parte do Programa Despertando Vocações Para as Licenciaturas PDVL, sobre o processo de internacionalização. Para isso, verificou-se as concepções do que é rede de cooperação, as dificuldades encontradas nas Escolas Agrotécnicas nas aplicações de ações que se caracterizem como internacionalização e o que mudou após a mudança para Institutos Federais. A pesquisa possui natureza exploratória com abordagem qualitativa com objetivo descritivo. Quanto aos procedimentos utilizou-se levantamentos bibliográficos, documentais e teve como instrumento de coleta de dados o formulário Webquest. Com as devidas respostas analisadas, observou-se que poucos discentes têm opiniões formadas sobre os que lhe foi indagado e foi constatado que $75 \%$ dos entrevistados opinaram que o IFPE utiliza de poucos recursos de internacionalização.
\end{abstract}

Palavras-Chave: Internacionalização, Institucionalização, Institutos Federais, Isomorfismo.

\section{Introdução}

A criação dos Institutos Federais de Educação, Ciência e Tecnologia, vêm sendo tema recorrente de debates sobre educação em todo território nacional. O surgimento dos Institutos

\footnotetext{
${ }^{1}$ Graduando em Licenciatura em Química; Instituto Federal de Pernambuco, silvanetofr@outlook.com

${ }^{2}$ Graduanda em Licenciatura em Química; Instituto Federal de Pernambuco, rayannelima-@hotmail.com

${ }^{3}$ Graduando em Licenciatura em Química; Instituto Federal de Pernambuco, eduardofragoso06@gmail.com

${ }^{4}$ Doutorado; Instituto Federal de Pernambuco,kilma.viana@vitoria.ifpe.edu.br

${ }^{5}$ Doutorando em Administração, Instituto Federal de Pernambuco, erick.viana@vitoria.ifpe.edu.br
} 
Federais fixa um vínculo com a valorização da educação e das instituições públicas, ao longo da existência das redes federais de educação profissional e tecnológica, os investimentos públicos feitos apontam um comportamento comum de governos no estado capitalista moderno, na qual visam qualificar a mão-de-obra para o mercado de trabalho.

Além deste cenário de uma sociedade capitalista, há uma preocupação com os elevados números de migração do campo para a cidade, ocasionando a busca por mecanismos para frear ou desacelerar o êxodo rural, passando a utilizar a educação como instrumento eficiente para realizar esta função. Neste contexto, além da educação rural como forma de "fixar" o homem no campo também é implantada a "extensão rural” no Brasil. (Brasil, 2009, p. 11.).

O surgimento das escolas Agrotécnicas federais (EAF) se deu na primeira metade do século XX, recebendo grandes influências dos setores agrícolas e industriais, oferecendo cursos de nível básico, médio e técnico. Mas a partir do ano de 2009 com a criação da Lei n 11.892/09 todas as EAF's se tornaram Instituto Federal de Educação, Ciência e Tecnologia, que aborda uma proposta de ensino verticalizado com diferentes níveis e modalidades.

\section{Fundamentação Teórica}

O Instituto Federal é hoje, mais que um novo modelo institucional, é a expressão maior da atual política pública de educação profissional brasileira. Está produzindo mudanças altamente significativas na vida e na história das instituições que optaram por aderir à proposta governamental, por esse motivo essas mudanças precisam ser acompanhadas bem de perto. $\mathrm{O}$ governo recebeu a missão de trabalhar com a nova característica, respeitando a história centenária das novas instituições mostrando uma nova institucionalidade adepta as políticas públicas e utilizar elas para simplificar o ingresso à educação profissional estipulando métodos de inclusão e permanência.

É com base em organizações internacionais tais como, Banco Interamericano de Desenvolvimento (BDI), por exemplo, que o Brasil teve que priorizar os investimentos na educação assim tornando-a mais profissional e com base técnica, tendo em vista um baixo custo, logo acessível para a maioria da sociedade e também em um curto período de tempo (SILVA.K.S., 2016).

Nessa perspectiva, PEREIRA afirma que:

(...) Destacamos, então, que a expansão da educação profissional e tecnológica se integra à agenda pública que prevê a presença do Estado na consolidação de políticas educacionais no campo da escolarização e da profisssionalização. Torna-se evidente a atuação do governo federal 
no sentido da expansão da oferta pública e da melhoria do padrão de qualidade da educação brasileira, em especial da educação profissional e tecnológica em todo o território nacional (ISAILMA, 2015, p.55).

Analisamos esta nova política aderida na educação pelo governo federal a preocupação na ampliação dos Institutos Federais para responder a uma procura pública em grande escala. Nesse trabalho buscaremos analisar sob o enfoque da Teoria Institucional e da Gestão do Conhecimento esse momento de transição de Escolas Agrotécnicas para Institutos Federais com foco em uma dimensão específica, a internacionalização.

A internacionalização das universidades tem sua origem na Idade Média, com a criação das primeiras escolas europeias (Paris, Bolonha, Oxford) que recebiam estudantes de várias partes do mundo e contavam com docentes igualmente estrangeiros, formando verdadeiras comunidades internacionais, reunidas em torno de um objetivo comum: o conhecimento (STALLIVIERI, apud CHARLE \& VERGER, 2004).

A busca pelo conhecimento sempre foi continua, por volta de 500 a. c. já existia o ensino superior na China, enquanto em 600 a. c. na Índia já existiam estabelecimentos de homens instruídos, o que indica ser origem da Universidade. Nos séculos XII e XIII firma-se o conceito de Universidade na Europa, nos séculos seguintes ocorre à propagação do conhecimento por áreas importantes (direito, teologia e medicina): o incentivo a mobilidade de estudantes e professores.

Para Tiffin (2007, p. 43) "um dos encantos da globalização das universidades é a proliferação de conferências internacionais. Aqui e no mundo pré e pós-conferências feitas por trocas de e-mail, as faculdades passaram a ser globais $[\ldots] "$..

A meta de internacionalizar a educação profissional resistente e institucionalizada produz desafios que precisam ser identificados e organizados por ordem de importância e possibilidade de resolução para que estes desafios desenvolvam experiências produtivas tornando os desafios, menos desafiantes. Sem estes tópicos há a chance de haver e de se repetir experiências de desapontamento tanto para os Institutos quanto para os parceiros que terão uma visão de falta de estrutura e sem preparo técnico-profissional, para firmar parcerias nas áreas de ensino, pesquisa e extensão, conhecidos como o "tripé da educação".

O termo internacionalização vem sendo tema central em discussões e debates no Brasil e no mundo. O destaque destes debates é a afirmação de que não á mais limites para a educação, pois os avanços tecnológicos e nas áreas da educação nos proporciona mudanças importantes na vida das pessoas. 
As relações internacionais são bastante diferentes no tema educação. Há variados conceitos que determinam o significado deste termo. Até então o mais utilizado nos anos oitenta definia internacionalização como atividades internacionais, trocas de experiências e investigação cientifica entre países.

Com o passar do tempo, novas definições foram surgindo. Knight (2003, p.2) propõe uma definição mais prática sobre o termo internacionalização, que seria "processo de integrar uma dimensão internacional, intercultural ou global com o objetivo, as funções e o oferecimento do ensino pós-secundário".

A expressão internacionalização vai desde a mobilidade estudantil, de servidores, participação em projetos de pesquisa e extensão, ampliação do aprendizado de línguas estrangeiras e novas culturas, desenvolvimento de novas tecnologias, compartilhar conhecimento através de ferramentas de Novas Tecnologias da Informação e Comunicação (NTIC'S) que nos permite uma aproximação com novos métodos pedagógicos em instituições parceiras e a troca de conhecimento sobre temas de interesse comum, formando redes de cooperação.

$\mathrm{O}$ processo de mudança organizacional dentro do sistema educacional de Escolas Agrotécnicas no procedimento de transição mostra dados adquiridos durante a experiência do desenvolvimento de institucionalização de ações de internacionalização em meio do Instituto Federal do campus Vitória de Santo Antão.

A teoria das organizações estuda o comportamento organizacional através de diversas perspectivas, neste trabalho escolhemos a perspectiva institucionalista, mais especificamente o isomorfismo institucional, onde as organizações estão inseridas em um processo de estruturação institucional.

Di Maggio e Powel (2006) conseguiram identificar três aspectos que por meio deles ocorre a mudança isomórfica institucional: i) Isomorfismo Coercitivo que provém das pressões ao mesmo tempo formais e informais, ii) Isomorfismo Mimético que resulta das respostas padronizadas sob condições de incerteza, iii) Isomorfismo Normativo que está associado à profissionalização. O isomorfismo Coercitivo diz respeito aos regulamentos e leis que de certa maneira padronizam e descrevem comportamentos. $\mathrm{O}$ isomorfismo Mimético faz a relação entre uma organização que de certo modo faz praticas espelhadas em outras organizações existentes por diversos motivos, que vão desde um maneira de se espelhar á objetivos ambíguos. O isomorfismo Normativo refere-se a organização que através de mecanismos buscam profissionalizar os indivíduos que nela fazem parte. 
O isomorfismo institucional explica a homogeneidade, investigando as diversas semelhanças nas práticas e formas organizacionais em campos institucionalmente legitimados. Esta linha de pensamento está baseada na racionalidade coletiva nos campos organizacionais. Segundo (Burrell e Morgan, 2001), a racionalidade coletiva nos campos organizacionais está ancorada na pressuposição de uma sociedade concreta, real e com um caráter sistêmico orientado para a ordem e regulação.

No ano de 2012, foi criado o Programa Internacional Despertando Vocações para as Licenciaturas (PDVL), ele surgiu de uma experiência exitosa na qual o IFPE fez parte. Além de despertar vocações para as licenciaturas, este programa também tem por objetivo formar uma rede de cooperação internacional. No desenvolver das ações do PDVL, outras instituições aderiram ao Programa ao longo do tempo. Participam das ações e colaboram para o alcance de objetivos e metas, atualmente, os Institutos Federais de Educação, Ciência e Tecnologia (IF's) de Pernambuco, Alagoas, Sertão Pernambucano, Piauí, Paraíba e Rondônia. Além das instituições nacionais, algumas instituições internacionais aderiram ao programa, como: Universidad de Mendoza - UM (Argentina), Universidad Tecnológica Nacional - UTN (Argentina), Univerdad Nacional de La Plata - UNLP (Argentina), Universidad de Playa Ancha - UPLA (Chile), Ministério da Educação do Panamá - MEDUCA (Panamá). Algumas ações foram desenvolvidas como: oficinas, visitas técnicas, jornadas de integração, feiras de profissões, simpósios, congressos, cursos de extensão internacional, todos na área de Formação de Professores em Química, Física, Matemática e Geografia (dependendo da instituição parceira).

\section{Metodologia}

Neste trabalho, a pesquisa desenvolvida é de natureza exploratória, quanto ao tipo de pesquisa, de acordo com Lakatos "a pesquisa exploratória são investigações de pesquisas empíricas cujo objetivo é a formulação de questões ou de problema, com tripla finalidade: desenvolver hipóteses, aumentar a familiaridade do pesquisador com um ambiente, fato ou fenômeno, para a realização de uma pesquisa futura mais precisa ou modificar e clarificar conceitos. Obtém- se frequentemente discrições tanto quantitativas quanto qualitativas do objeto de estudo, e o investigador deve conceituar as inter-relações entre as propriedades do fenômeno, fato ou ambiente observado" (2007, pág. 187 e 188).

A pesquisa foi desenvolvida através de uma abordagem exploratória acerca das respostas dos docentes. O campo de pesquisa foram os discentes do $2^{\circ}(11), 4^{\circ}(3)$ e $6^{\circ}(3)$ período 
do IFPE - Campus Vitória de Santo Antão, alunos do curso de licenciatura em química e membros do Programa Internacional Despertando Vocações para as Licenciaturas - PDVL, totalizando 17 estudantes. A pesquisa ocorreu no intervalo de tempo de dois dias, 27 e 28 de setembro de 2016.

Foi utilizado como instrumento de pesquisa um formulário Webquest semiestruturado através do Google Docs. Pretendeu-se com esses sujeitos de pesquisa obter as concepções sobre internacionalização, se a instituição onde os mesmos estão inseridos realiza práticas que facilitem o desenvolvimento de ações que possam ter caráter de rede de cooperação internacional, se havia percepção de mudança organizacional. O convite para participar da pesquisa se deu através de mídia virtual (WhatsApp). Do total de 35 estudantes participantes do grupo obteve-se a resposta de 17 (46\%).

\section{Resultados e Discussão}

Ao analisarmos os dados colhidos no formulário que foi respondido pelos discentes, podemos constatar que em relação ao nível de internacionalização $50 \%$ responderam que o Instituto Federal de Pernambuco- Campus Vitória tem um médio nível de internacionalização. Como podemos constatar no gráfico abaixo:

Gráfico 1. Nível de internacionalização da instituição.

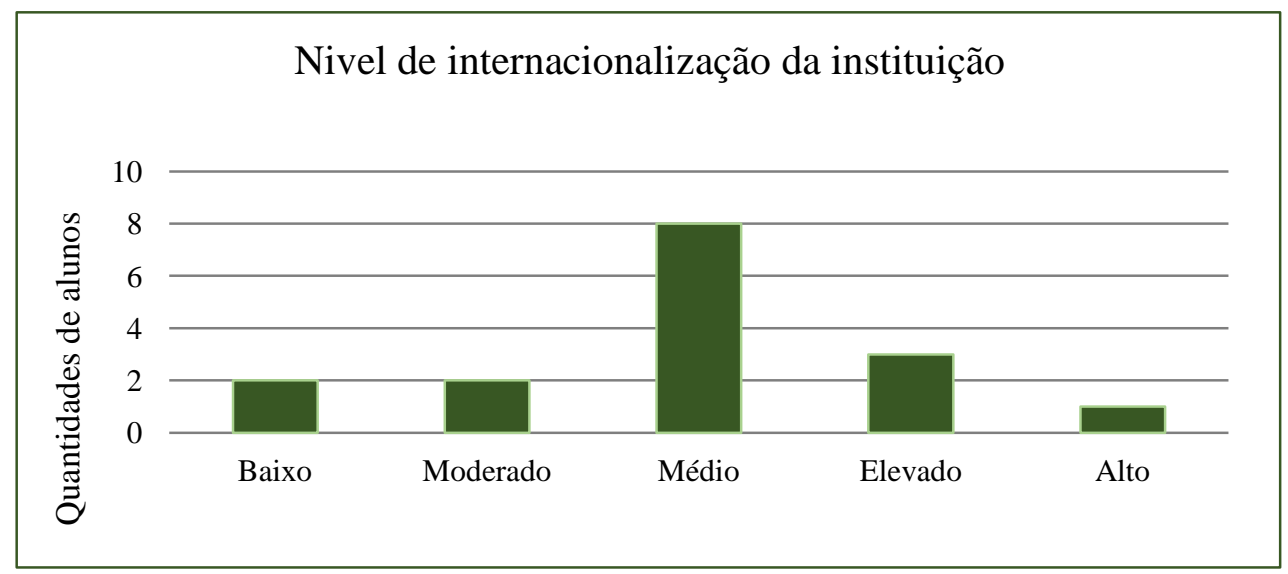

Fonte: Elaboração do autor. 
Com relação ao que eles acham sobre internacionalização, a maioria das respostas foram direcionada a intercâmbio e a interação com novas culturas, como podemos observar em algumas das respostas abaixo:

Estudante A: "Uma experiência construtiva com novas culturas, hábitos, ou seja, viver um novo momento oportuno para o crescimento profissional”.

Estudante B: "O termo Internacionalização pode nos dar diferentes perspectivas, sobre o real significado da palavra, vai desde a mobilidade internacional de alunos $e$ servidores, a estudar novas línguas e aprender sobre novas culturas, desenvolvimento de novas tecnologias, desenvolvimento de trabalhos científicos, etc."

Quando os discentes foram indagados sobre "Quais atividades podem caracterizar uma instituição internacionalizada?", ficou distribuído em três ações, que foram a de mobilidade, congressos internacionais e troca de saberes culturais. Podemos observar na resposta desse estudante.

Estudante C: "Instituições que formam parcerias com outras instituições fora do país, através de programas que possibilitem a participação em congressos, mobilidade, que venham conhecer novas culturas".

Um dos mais importantes aspectos que leva uma instituição se tornar internacionalizada é mediar o contato de seus discentes e gestores com os de outras instituições.

Em relação ao escrito a cima foi feito a seguinte pergunta: "Você já teve contato com algum estudante/docente/pesquisador estrangeiro através de sua instituição?’. A resposta está demonstrada no gráfico abaixo.

Gráfico 2: Relação de contato com estudantes e gestores estrangeiros.

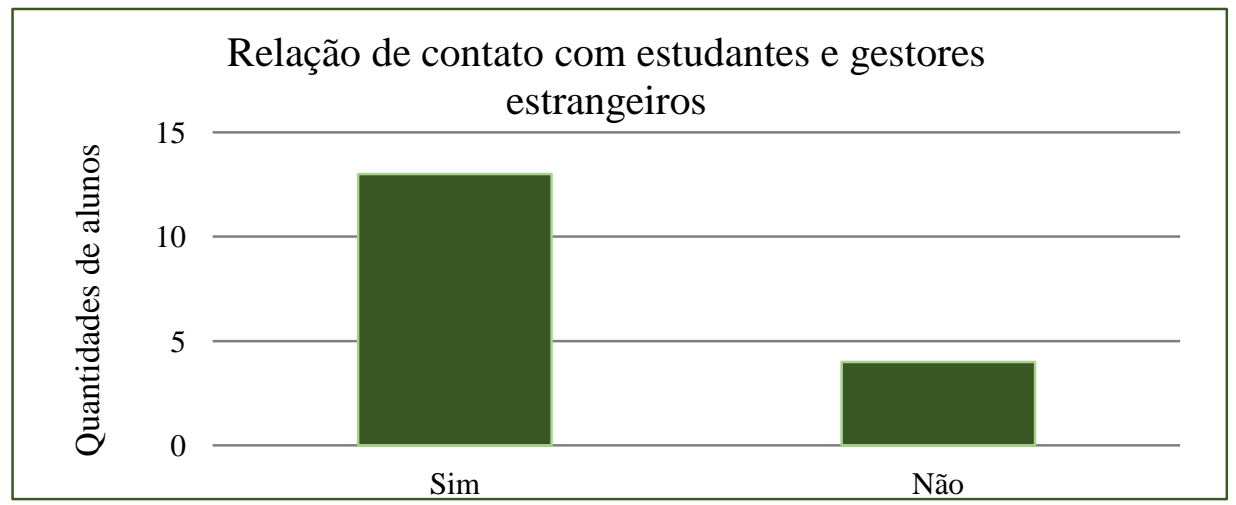

Fonte: Elaboração do autor. 
Neste gráfico acima, de acordo com os discentes que responderam o questionário, é perceptível o déficit de parceiras do Instituto Federal com outras universidades internacionais, para facilitar as práticas de internacionalização.

Neste gráfico podemos observar a resposta dos discentes acerca das perguntas relacionadas às atividades remuneradas que os próprios desenvolvem dentro ou fora da instituição. A maioria dos discentes ou desenvolvem ações como bolsista (remunerado) ou nenhuma atividade remunerada e apenas um (1) é estagiário.

Gráfico 3: Desenvolve alguma atividade remunerada.

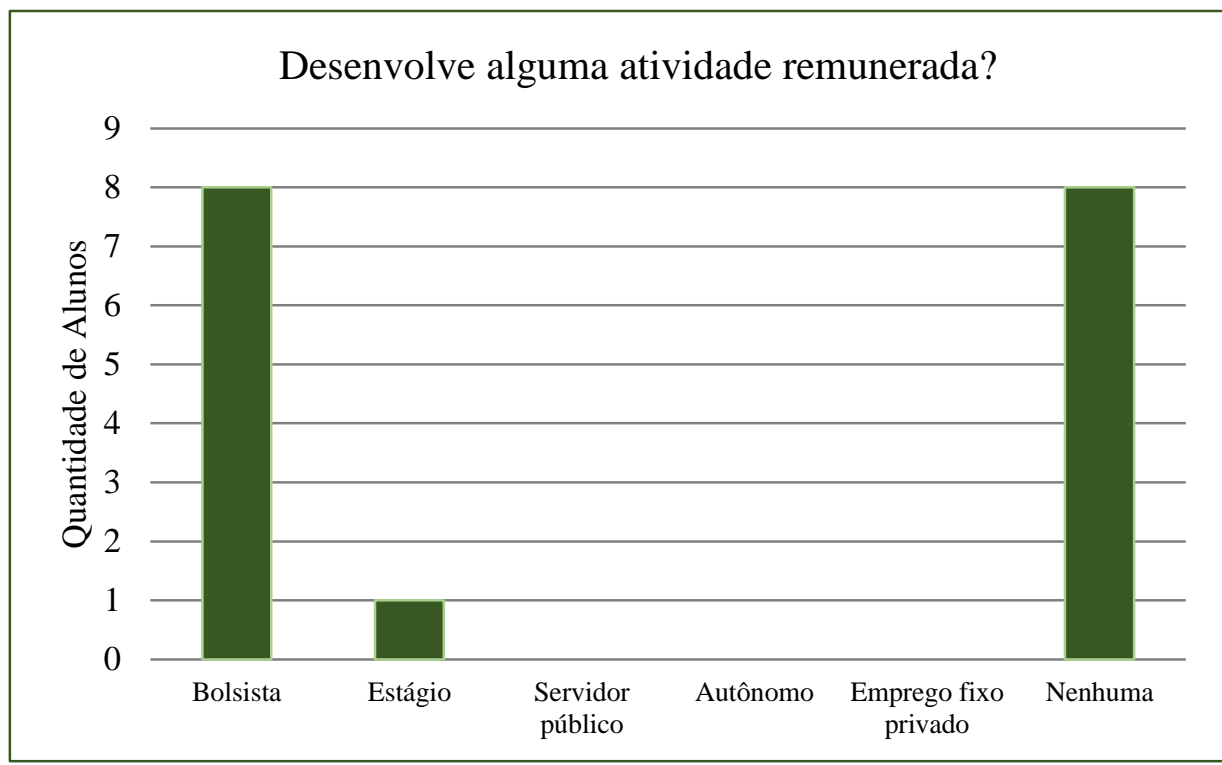

Fonte: Elaboração do autor.

Gráfico 4: Sua instituição realiza eventos internacionais.

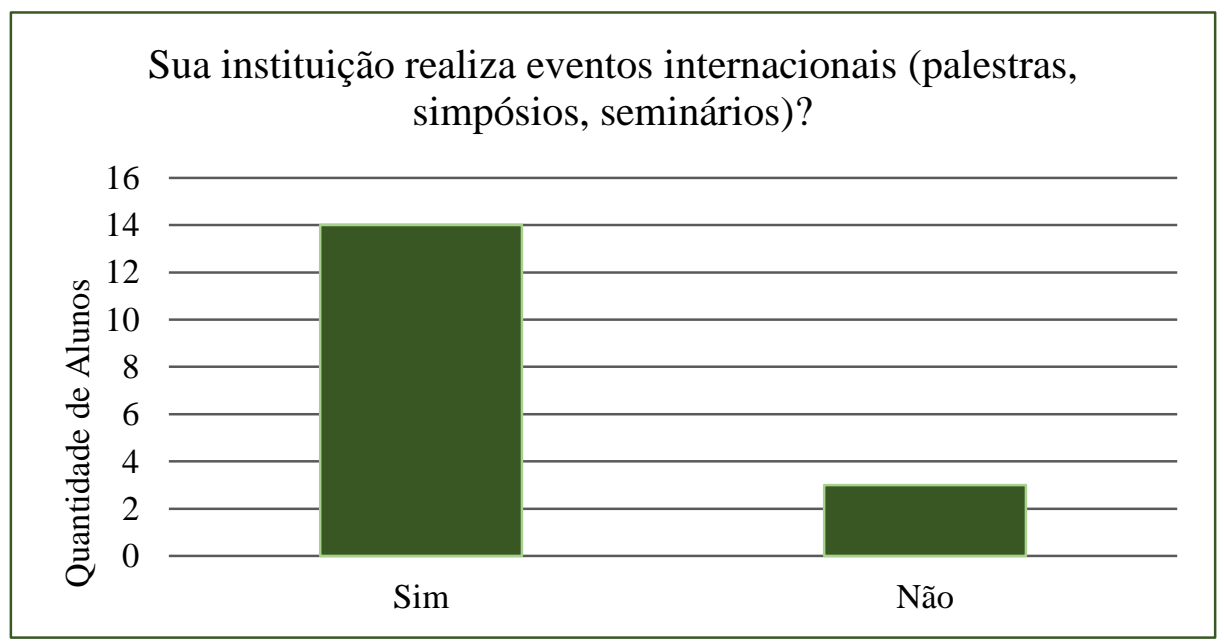

Fonte: Elaboração do autor. 


\section{Conclusões}

Com as indagações feitas aos discentes do Instituto Federal de Pernambuco - Campus Vitória observou-se que o instituto ainda tem um déficit em relação as práticas de internacionalização. Em relação a rede de cooperação os alunos responderam que há uma certa cooperação entre os Institutos Federais mais próximos.

Através dos estudos e leituras feitas na elaboração deste trabalho ficou claro que à mudança organizacional que ocorreu de EAF's para IF's houve uma grande melhora na estrutura e ensino, fazendo com que o Instituto Federal se tronasse um dos grandes pivôs da educação e do ensino-aprendizagem.

\section{Referências}

BRASIL (Mec/Setec). Significação do Ensino Agrícola da Rede Federal de Educação Profissional e Tecnológica. Brasília DF, abril de 2009.

BURRELl, G.; MORGAN, G. (2001). Sociological Paradigms and Organizational Analysis. Aldershot, UK. Ashgate Publishing Co.

DI MAGGIO, P. J., \& POWELL, W. W. (2006) Jaula de ferro revisitada: isomorfismo institucional e racionalidade coletiva nos campos organizacionais. in: Caldas, M. P.; Bertero, C. O. (coord.) Teoria das organizações. S. Paulo. Atlas.

NEVES, L. M. W. “A sociedade civil como espaço estratégico de difusão da nova pedagogia da hegemonia". In: NEVES, L. M. W. (Org). A Nova Pedagogia da Hegemonia: estratégias do capital para educar o consenso. São Paulo, S.P: Xamã, 2005, p. 85-126.

PEREIRA, Maria Isailma B. Processos de gestão em transformação: Os institutos federais de educação, ciência e tecnologia como "arena política.” 2015, 284 páginas.

STALLIVIERI, Luciane. Estratégias de Internacionalização das Universidades Brasileiras. Caixas do Sul: EDUCS, 2004.

TIFFIN, John; RAJASINGHAM, Lalita (Org.). A universidade virtual e global. Porto Alegre: Artmed, 2007. 